\title{
Agronomic Characteristics of Induced Pepper Germplasm in 2015 at Thua Thien Hue
}

\author{
Hai Thi Hong Truong ${ }^{1,2}$, Ngoc Lan Phung ${ }^{1}$ and Thao Thu Phan ${ }^{2}$ \\ 1. Department of Biotechnology, Agronomy Faculty, College of Agriculture and Forestry, Hue University, 102 Phung Hung, Hue \\ 47000, Vietnam \\ 2. Hue University, 03 Le Loi, Hue 47000, Vietnam
}

\begin{abstract}
The agronomical characteristics of 14 induced pepper accessions from Korea were evaluated in spring-summer in 2015 at Thua Thien Hue in order to select pepper lines having high yield and good adaptation under local conditions for introducing new cultivar to enhance plant productivity and quality. Most of the accessions showed growth duration suitable to cropping pattern in Thua Thien Hue. Large variation in agronomical characteristics, such as plant height, number of leaves and branches, stem and flower color and fruit shape were observed among these induced pepper accessions. Plant height of all induced pepper accessions was higher than control check, ranging from $49.2 \mathrm{~cm}$ to $105.0 \mathrm{~cm}$. YT2-1 had the highest fruit set rate (80.38\%). All pepper accessions had higher yield compared with the control check (1.42 tons/ha), ranging from 3.71 tons/ha (YT4-1) to 28.34 tons/ha (YT4-3). YT1-2 had good characteristics and good quality. YT1-1 showed high resistance to insects and diseases. These accessions are potentially useful for breeding programme.
\end{abstract}

Key words: Germplasm, pepper, Capsicum annumm, Thừa Thiên Huế.

\section{Introduction}

Hot pepper (Capsium annum L.) belonging to family Solanaceae is an important cash crop used widely as spice trade in the world. Peppers (dry and green) were cultivated in 2011 about 3.8 million ha, out of which 3.3 million ha in developing and less developed countries of Asia (2.5 million ha) and Africa $(0.8 \mathrm{~m} \mathrm{ha})$ [1]. Spice pepper is produced in great amount in the world [2]. Pepper contains more vitamins $C$ than any other vegetable crop [3] and is also source of minerals ( $\mathrm{Ca}, \mathrm{Fe}, \mathrm{Na}, \mathrm{P}, \mathrm{S}$ ), amino acids (thiamin, axit oxalic, riboflavin...), proteins and lipids [4]. Recently, pepper becomes commercial products because of industrial process as chilli food (powder, pepper sauce...) and is considered as medicinal plant used in traditional medicine for several stimulating, antiseptic, digestive, disinfectant and anti-inflammatory functions [5].

Corresponding author: Hai Thi Hong Truong, Ph.D., research field: molecular genetics.
Hot pepper is a high economic traditional spicy vegetable and is cultivated popularly through Vietnam. Since 1995, some provinces have gotten high income due to that large area of pepper produce provides raw material for food factories and companies for consuming and exporting $[6,7]$. Being one of mainly provinces for growing pepper, Thua Thien Hue has taken advantages of large sandy soil area to develop this spice crop. Thus, promoting pepper production has been a good condition to efficiently utilize land by intercropping or rotated cropping and also be a chance to utilize labour resource in Thua Thien Hue. However, local pepper varieties, such as Chia Voi and Sung Bo, which have low yield and infected disease, are popularly used by farmers in here. In addition, local farmers used to keep the seeds for next sowing seasons by themselves. This made seed contaminated and low yield. To develop pepper becoming commercial crop in this province, the selection of variety is the most important step. Thus, the present 
study aimed to evaluate adaptability of induced hot pepper germplasm to local conditions and to select good lines based on their morphological and agronomical characters to provide good pepper line for breeding study and cropping in Thua Thien Hue.

\section{Materials and Methods}

\subsection{Materials}

Fourteen pepper lines collected from National Institute of Horticultural and Herbal Science (NIHHS) in Korea and one local variety (Chia Voi) as control were used in this study (Table 1).

\subsection{Methods}

\subsubsection{Experimental Design, Time and Place}

This experiment was designed in complete randomized design (CRD) without replication. Each plot had double rows with 16 plants. Spacing of $40 \mathrm{~cm}$ and $60 \mathrm{~cm}$ between plants and rows was used, respectively. Thirty days after sowing, seedlings were transplanted to open field. The cultivated techniques based on documents of national technical regulations on testing for value of cultivation and use of hot pepper and sweet pepper varieties of Ministry of Agriculture and Rural Development (QCVN 01-64: 2011/BNNPTNT) [8]. The experiment was conducted

Table 1 List of peper accessions used.

\begin{tabular}{lll}
\hline No. & Name of accessions & Place of collection \\
\hline 1 & YT1 & NIHHS \\
2 & YT2 & NIHHS \\
3 & YT3 & NIHHS \\
4 & YT4 & NIHHS \\
5 & KR1-1 & NIHHS \\
6 & KR1-2 & NIHHS \\
7 & KR1-3 & NIHHS \\
8 & KR1-4 & NIHHS \\
9 & YT1-1 & NIHHS \\
10 & YT1-2 & NIHHS \\
11 & YT2-1 & NIHHS \\
12 & YT4-1 & NIHHS \\
13 & YT4-2 & NIHHS \\
14 & YT4-3 & NIHHS \\
15 & Chia Voi (control) & Thua Thien Hue \\
\hline
\end{tabular}

from January to May 2015 at greenhouse of Agronomy Faculty, Hue University of Agriculture and Forestry.

\subsubsection{Agronomy Characteristic Collection}

Characteristics include morphological, plant structure, ability of growth, flowering, fruiting, setting seeds, fruit qualities, levels of pest and insects infected and productivity of pepper germplasm. Fruit qualities were found by some characteristics as fruit length, fruit width, wall thickness, fruit color, Brix, dry matter content and pungency. Quantitative and qualitative parameters observed, weighed or measured were used. Data were collected from five growth plants for each line. Predicted yield was formed by mean of fruit weight, number fruits per plant and the density of 40,000 individuals per ha. Actual yield (ton/ha) was calculated by total of fruits weight per ha. The rate of fruits infected or harmed by some diseases or insects, such as anthracnose or fruitworm, were calculated as Eq. (1):

The rate of fruits infected or harmed $(\%)=$ (number of infected or harmed fruits)/

(total of fruit observed)

The rate of cutworm and beet armyworm was recorded by number of individuals $/ \mathrm{m}^{2}$.

\subsubsection{Analysis Method}

Data were analyzed by Excel 2007, and evaluation of stability and adaptability was considered by standard deviation value (SD).

\subsection{Weather Conditions during This Experiment}

Table 2 showed the effect of weather conditions on the ability of the growth and the development of peper. Seedlings were affected by low temperature $\left(19.5^{\circ} \mathrm{C}\right)$ mostly in rainy days in January. In February, high number of rainy days, high humidity and low temperature impacted on tilling and transplanting. Temperature increasing and the most rainfall appearing in March influenced the periods of flowering and fruiting. The mean temperature and humidity reaching $25.9^{\circ} \mathrm{C}$ and $87 \%$ in April, respectively, were favourable 
Table 2 Some meteorological conditions recorded in spring-summer season 2015.

\begin{tabular}{|c|c|c|c|c|c|c|c|c|c|c|c|}
\hline \multirow{2}{*}{ Month } & \multicolumn{3}{|c|}{ Temperature $\left({ }^{\circ} \mathrm{C}\right)$} & \multicolumn{2}{|c|}{ Rainfall (mm) } & \multicolumn{2}{|c|}{ Humidity (\%) } & \multirow{2}{*}{$\begin{array}{l}\text { Evaporation } \\
(\mathrm{mm})\end{array}$} & \multirow{2}{*}{$\begin{array}{l}\text { Total sunny } \\
\text { hour }(\mathrm{h})\end{array}$} & \multicolumn{2}{|c|}{ Number of Number of } \\
\hline & $\mathrm{T}_{\text {mean }}$ & $\mathrm{T}_{\max }$ & $\mathrm{T}_{\min }$ & NRD & $\mathrm{R}_{\text {mean }}$ & $\mathrm{H}_{\text {mean }}$ & $\mathrm{H}_{\text {min }}$ & & & $\begin{array}{l}\text { stormy } \\
\text { day (d) }\end{array}$ & $\begin{array}{l}\text { drought day } \\
\text { (d) }\end{array}$ \\
\hline January & 19.5 & 29.1 & 13.3 & 12 & 70.8 & 89 & 56 & 47.4 & 119 & 0 & 0 \\
\hline February & 21.8 & 33.5 & 14.5 & 11 & 64.2 & 90 & 61 & 44.5 & 135 & 2 & 0 \\
\hline March & 25.1 & 35.8 & 18.6 & 6 & 180.1 & 88 & 48 & 64.3 & 167 & 1 & 2 \\
\hline April & 25.9 & 39.0 & 16.1 & 10 & 151.7 & 87 & 44 & 67.6 & 198 & 3 & 3 \\
\hline $\begin{array}{l}\text { May (1st-10th } \\
\text { day) }\end{array}$ & 29.1 & 37.0 & 23.5 & 3 & 10.8 & 79 & 52 & - & 85 & - & - \\
\hline
\end{tabular}

Source: Center for Hydrometeorology Forecast of Thua Thien Hue Province, 2015.

NRD: number of rainy days; $\mathrm{H}$ : humidity.

Table 3 Growth and development periods of pepper germplasm.

\begin{tabular}{lllll}
\hline \multirow{2}{*}{ Accession } & \multicolumn{3}{c}{ Time from transplant to... (days) } \\
\cline { 2 - 5 } YT1 & Branching & Flowering & 1st harvesting & 2nd harvesting \\
YT2 & 20 & 31 & 81 & 104 \\
YT3 & 21 & 31 & 81 & 104 \\
YT4 & 21 & 31 & 81 & 104 \\
YT1-1 & 21 & 31 & 81 & 104 \\
YT1-2 & 21 & 31 & 81 & 104 \\
YT2-1 & 21 & 31 & 81 & 104 \\
YT4-1 & 31 & 81 & 104 \\
YT4-2 & 23 & 36 & 89 & 104 \\
YT4-3 & 23 & 39 & 89 & 104 \\
KR1-1 & 23 & 39 & 89 & 104 \\
KR1-2 & 21 & 31 & 81 & 104 \\
KR1-3 & 19 & 31 & 81 & 104 \\
KR1-4 & 19 & 31 & 89 & 104 \\
Control & 19 & 31 & 96 & 104 \\
\hline
\end{tabular}

for growth and development of pepper. However, the most of number of rainy days (10 d) occurred in May taking advantage for the development of anthracnose. In May, temperature at $29.1{ }^{\circ} \mathrm{C}$, humidity at $79 \%$ and suitable rainfall promoted fruit ripen and harvest.

\section{Results and Discussion}

\subsection{Time of Growth and Development}

Time of growth and development is decided by genetic characters and conditions, such as water, temperature, humidity, light and cultivated techniques. The identification of growth time helps to control crops to usefully suit land and climate conditions of each production area. Time to finish periods of the growth and development is showed in Table 3. Time from transplant to appear the first branch ranged from $19 \mathrm{~d}$ to 23 d. KR1-1, KR1-2 and KR1-3 accessions showed the earliest time of branching $(19 \mathrm{~d})$, followed by YT1 (20 d). Whereas, YT2-1, YT4-1 and YT4-2 accessions had the latest time of branching with $23 \mathrm{~d}$ and the remaining accessions started branching at $21 \mathrm{~d}$.

Control check had the latest time of flowering by 41 d. Almost flowering time of pepper lines was $31 \mathrm{~d}$ and earlier than control, except YT4-1 (36 d), YT4-2 and YT4-3 (39 d).

Most of accessions gave fruits at $81 \mathrm{~d}$ after transplanting to open field. YT4-1, YT4-2, YT4-3 and KR1-4 accessions fruited at $89 \mathrm{~d}$. Whereas, fruiting of KR1-1 and control accessions was at $96 \mathrm{~d}$. Although KR1-1 had flowering time earlier, but fruited the latest. Follow observing, there were nine lines riped at the 
same time (81 d after transplanting). KR1-1 and control check had the latest time of harvesting (Table 3 ).

\subsection{Vegetative Characteristics}

Table 4 recorded the results of vegetative characteristics on pepper germplasm. Plant canopy width is ability for occupation spacing of plant and potentiality of branch distribution. This is meant to be suitable for disposition density of each variety. YT1-2 had the widest canopy diameter $(91.6 \mathrm{~cm})$, followed by YT2, YT1 and YT4-3 with 87.6, 81.6 and $80.6 \mathrm{~cm}$, respectively. The narrowest was observed in control $(30.8 \mathrm{~cm})$. The remaining accession had plant canopy width ranging from $50 \mathrm{~cm}$ to $80 \mathrm{~cm}$.

The plant height was different among pepper accessions. YT1 had the highest plant $(105 \mathrm{~cm})$ and control accession had the lowest plant height $(37 \mathrm{~cm})$. The plant height of remaining accessions ranged from $49 \mathrm{~cm}$ to $90 \mathrm{~cm}$. Number of leaves per stem was recorded approximately 12 leaves in YT4, YT1-1 and YT1-2. YT3, YT4-1 and YT4-2 lines had number of leaves equal with the control. The lowest number of leaves was observed in KR1-3 and KR1-4 (9.2 leaves).

Total of branches per plant ranged from 21 to 86 . YT1-2 had the highest number of branch $(86.2$ branches), next one was YT4-3 (82.8 branches) and
YT1-1 (82.6 branches). Control accession had the lowest number of branches (21.6 branches).

\subsection{Flowering and Fruiting Ability}

Characters of flowering and fruiting of pepper germplasm were presented in Table 5. The highest number of flowers belonged to YT4-3 (193.2 flowers), followed by YT1-1, KR1-2 and YT1 with 155.2, 140.8 and 133.6 flowers, respectively. Percentage of efficient flower ranged from $28.82 \%$ (control) to $80.38 \%$ (YT2-1). Number of efficient fruits varied widely from 9.2 fruits to 116 fruits. YT1 and control check had the lowest number of fruit (approximately 9 fruits), whereas YT4-3 reached 116 fruits and YT1-1 line got 91.2 fruits per plant. Number of fruits of remaining accessions ranged from 39.1 to 68.2. Percentage of fruiting was low at almost accessions ranging from $20 \%$ to $60 \%$. The highest rate was found in YT1-2 line (68.20\%), next was YT4-3 (60.25\%) and YT1-1 (58.76\%). Whereas, YT1 only had $6.88 \%$ of fruiting.

\subsection{Morphological Traits}

Morphological characters of flower, fruit and seed are the main features of genotype distinguishing varieties' difference. Morphological traits were detected in a wide variation presented in Table 6.

Table 4 Vegetative characteristics of pepper germplasm.

\begin{tabular}{lllll}
\hline Accession & Plant height $(\mathrm{cm})$ & Plant canopy width $(\mathrm{cm})$ & Number of leaves/stem & Total of branches \\
\hline YT1 & $105.0 \pm 5.0$ & $81.6 \pm 5.7$ & $10.6 \pm 0.4$ & $70.8 \pm 8.9$ \\
YT2 & $90.0 \pm 3.6$ & $87.6 \pm 6.9$ & $10.2 \pm 0.2$ & $41.4 \pm 4.5$ \\
YT3 & $61.6 \pm 6.8$ & $65.6 \pm 1.9$ & $11.8 \pm 0.7$ & $41.8 \pm 9.2$ \\
YT4 & $66.6 \pm 4.2$ & $69.2 \pm 5.2$ & $12.0 \pm 1.4$ & $52.4 \pm 5.5$ \\
YT1-1 & $71.2 \pm 8.8$ & $77.4 \pm 8.8$ & $12.6 \pm 1.3$ & $82.6 \pm 8.2$ \\
YT1-2 & $91.8 \pm 13.7$ & $91.6 \pm 17.3$ & $12.0 \pm 1.3$ & $86.2 \pm 11.9$ \\
YT2-1 & $58.6 \pm 4.2$ & $66.6 \pm 5.2$ & $10.6 \pm 0.7$ & $38.6 \pm 3.7$ \\
YT4-1 & $49.2 \pm 5.4$ & $65.2 \pm 5.8$ & $11.8 \pm 1.1$ & $41.2 \pm 4.9$ \\
YT4-2 & $65.4 \pm 3.3$ & $65.2 \pm 5.8$ & $11.8 \pm 1.1$ & $66.0 \pm 21.2$ \\
YT4-3 & $87.8 \pm 13.5$ & $80.6 \pm 8.1$ & $11.6 \pm 1.8$ & $82.8 \pm 8.6$ \\
KR1-1 & $56.6 \pm 2.9$ & $59.2 \pm 4.8$ & $11.2 \pm 0.5$ & $48.4 \pm 7.1$ \\
KR1-2 & $54.8 \pm 5.8$ & $54.2 \pm 5.4$ & $10.4 \pm 0.5$ & $46.8 \pm 11.9$ \\
KR1-3 & $57.2 \pm 3.6$ & $59.8 \pm 6.9$ & $9.2 \pm 0.4$ & $35.6 \pm 5.0$ \\
KR1-4 & $55.6 \pm 5.0$ & $59.8 \pm 6.9$ & $9.2 \pm 0.4$ & $46.0 \pm 9.2$ \\
Control & $37.0 \pm 11.5$ & $30.8 \pm 8.9$ & $11.8 \pm 0.5$ & $21.6 \pm 9.2$ \\
\hline
\end{tabular}


Table 5 Characteristics of flowering and fruiting ability of pepper germplasm.

\begin{tabular}{lllll}
\hline Accession & $\begin{array}{l}\text { Number of flowers } \\
\text { per plant }\end{array}$ & $\begin{array}{l}\text { Percentage of efficient } \\
\text { flowers (\%) }\end{array}$ & $\begin{array}{l}\text { Number of efficient } \\
\text { fruits per plant }\end{array}$ & $\begin{array}{l}\text { Percentage of } \\
\text { fruiting (\%) }\end{array}$ \\
\hline YT1 & $133.6 \pm 6.06$ & 54.69 & 9.2 & 6.88 \\
YT2 & $127.0 \pm 38.63$ & 69.76 & 54.1 & 42.59 \\
YT3 & $92.6 \pm 68.08$ & 66.95 & 39.1 & 42,22 \\
YT4 & $105.4 \pm 23.45$ & 76.66 & 51.8 & 49.15 \\
YT1-1 & $155.2 \pm 90.96$ & 80.28 & 91.2 & 58.76 \\
YT1-2 & $100.0 \pm 29.98$ & 67.60 & 68.2 & 68.20 \\
YT2-1 & $104.0 \pm 30.00$ & 80.38 & 55.2 & 53.08 \\
YT4-1 & $79.4 \pm 37.96$ & 45.59 & 17.2 & 21.66 \\
YT4-2 & $101.6 \pm 64.08$ & 71.65 & 49.8 & 49.02 \\
YT4-3 & $193.2 \pm 33.17$ & 77.74 & 116.4 & 60.25 \\
KR1-1 & $114.8 \pm 50.43$ & 65.68 & 41.2 & 35.89 \\
KR1-2 & $140.8 \pm 114.30$ & 67.90 & 53.8 & 38.21 \\
KR1-3 & $84.0 \pm 14.27$ & 66.43 & 41.0 & 48.81 \\
KR1-4 & $115.4 \pm 33.65$ & 72.27 & 42.6 & 36.92 \\
Control & $34.0 \pm 14.44$ & 28.82 & 9.4 & 27.65 \\
\hline
\end{tabular}

Table 6 Morphological characteristics of pepper germplasm.

\begin{tabular}{|c|c|c|c|c|c|c|c|}
\hline \multirow{2}{*}{ Accession } & \multirow{2}{*}{$\begin{array}{l}\text { Pedicle position at } \\
\text { anthesis }\end{array}$} & \multirow{2}{*}{$\begin{array}{l}\text { Pedicle position } \\
\text { at fruiting }\end{array}$} & \multicolumn{5}{|c|}{ Colour } \\
\hline & & & Stem & Leaf & Node & Unripe fruit & Ripe fruit \\
\hline YT1 & Pendant & Pendant & Dark green & Dark green & Dark violet & Dark green & Dark red \\
\hline YT2 & Pendant & Pendant & Light green & Green & Violet & Light green & Bright red \\
\hline YT3 & Pendant & Pendant & Green & Dark green & Light violet & Green & Bright red \\
\hline YT4 & Pendant & Pendant & Green & Dark green & Violet & Light green & Scarlet \\
\hline YT1-1 & Pendant & Pendant & Light green & Light green & Light violet & Green & Scarlet \\
\hline YT1-2 & Pendant & Pendant & Green & Dark green & Light violet & Green & Scarlet \\
\hline YT2-1 & Pendant & Pendant & Light green & Green & Dark violet & Light green & Bright red \\
\hline YT4-1 & Pendant & Pendant & Green & Dark green & Violet & Light green & Bright red \\
\hline YT4-2 & Pendant & Pendant & Light green & Green & Light violet & Light green & Bright red \\
\hline YT4-3 & Intermediate & Erect & Green & Dark green & Violet & Green & Bright red \\
\hline KR1-1 & Pendant & Pendant & Green & Green & Light violet & Light green & Dark red \\
\hline KR1-2 & Pendant & Pendant & Green & Green & Violet & Light green & Scarlet \\
\hline KR1-3 & Pendant & Pendant & Green & Green & Violet & Green & Dark red \\
\hline KR1-4 & Pendant & Pendant & Green & Green & Dark violet & Green & Scarlet \\
\hline Control & Pendant & Pendant & Light green & Light green & Green & Light green & Orange \\
\hline
\end{tabular}

Pedicle position at anthesis and fruiting are concluded as pendant, intermediate or erect. All accessions had pendant flower and fruit, except YT4-3, which had intermediate flower habit and erected fruit. The colour of stem included dark green (YT1), light green (YT2, YT1-1, YT2-1, YT4-2, control) and green (the remained lines). YT1, YT3, YT4, YT1-2, YT4-1 and YT4-3 had dark green leaf, whereas light green leaves were observed in YT1-1 and control check and green colour was found in remained lines. Dark green stem and leaves indicated earning high sunlight ability and strong photosynthesis.

The colour of node varied from light violet to dark violet. YT1, YT2-1 and KR1-4 lines had dark violet node, but the lighter one was observed in YT3, YT1-1, YT1-2, YT4-2 and KR1-1. Nodes of all remained lines were violet, except the control check which had green stem.

In the immature stage, colour of fruit was diversed from light green to dark green. Only YT1 line had dark green fruit. Green fruits were found in YT3, YT1-1, YT1-2, YT4-3, KR1-3 and KR1-4. The 
remained accessions had light green fruits. In the mature stage, fruit colour changed from bright red, scarlet to dark red. Only fruits of the control check had orange color. Fruits which had bright red were observed in YT2, YT3, YT2-1, YT4-1, YT4-2 and YT4-3. Fruits of YT4, YT1-1, YT1-2, KR1-2 and KR1-4 had scarlet and the remained accessions had dark red, such as YT1, KR1-1 and KR1-3. Scarlet and bright red are the main colour of mature fruit, because they suit demands of consumers, industrial process and exporting.

The results indicated that YT1-2, YT4-3 and YT1-1 showed morphological traits better than the other lines.

\subsection{Qualitative Characters of Fruit}

According to Bosland $[9,10]$, chilli are usually classified based on fruit characteristic, including pungency, color, shape, flavor, size and use. Fruit's qualitative characteristics of pepper germplasm were shown in Table 7. Fruit length ranged from $6.53 \mathrm{~cm}$ to $11.28 \mathrm{~cm}$. The control check obtained the longest fruit $(11.28 \mathrm{~cm})$, next ones were YT4-2 $(10.97 \mathrm{~cm}), \mathrm{KR} 1-3$ $(10.86 \mathrm{~cm})$ and YT4 $(10.32 \mathrm{~cm})$. The remained accessions had almost equal fruit length from $7.47 \mathrm{~cm}$ to $9.8 \mathrm{~cm}$. Fruit width was the lowest in YT4-3 (1.38 $\mathrm{cm})$ and the highest in YT4 $(2.3 \mathrm{~cm})$. Fruit width was greater than $2.0 \mathrm{~cm}$ in YT1, YT2-1, YT4-2, KR1-3 and control accession. Large fruit is more suitable for processing pepper [11].

Fruit wall thickness was different among accessions. Fruit of accessions had thick wall, such as YT1 (0.21 $\mathrm{cm})$, YT4 $(0.21 \mathrm{~cm}), \mathrm{KR} 1-3(0.21 \mathrm{~cm})$ and YT4-2 $(0.2$ $\mathrm{cm})$. The remained accessions had fruit wall thickness from $0.15 \mathrm{~cm}$ to $0.19 \mathrm{~cm}$. Brix is indicator to express content of solube solid. KR1-1 had the highest Brix (10.7), followed by YT1-2 (10). YT4-2 and control check had the lowest Brix at 4.1 and 5.8, respectively.

Dry matter content calculated by weight of $100 \mathrm{~g}$ of fresh fruit is one of qualitative demands for exporting pepper powder. The higher dry matter content is, the higher amount of dry powder gets. KR1-3 had the highest dry matter content at $16.88 \%$, followed by YT1-2 at $15.22 \%$. The remained accessions had dry matter content over $10 \%$ except for YT4-2, KR1-1 and control check.

Pungent fruit is characterized for hot pepper. Pungency of YT1-1, YT1-2 and YT4-3 was higher that the control check. Flavor is meaning specific taste of fruit and takes appetite for customers. Flavor assessment had good results in almost accessions, except for YT2, YT3, YT2-1, YT4-1, YT4-2 and KR1-2.

Table 7 Qualitative characteristics of pepper germplasm.

\begin{tabular}{lllllllll}
\hline Accession & Fruit length $(\mathrm{cm})$ & $\begin{array}{l}\text { Fruit width } \\
(\mathrm{cm})\end{array}$ & $\begin{array}{l}\text { Fruit wall } \\
\text { thickness }(\mathrm{cm})\end{array}$ & Brix & $\begin{array}{l}\text { Dry matter } \\
\text { content }(\%)\end{array}$ & Flavor & Fruit pungency & Dry fruit color \\
\hline YT1 & $8.79 \pm 1.42$ & $2.16 \pm 0.26$ & $0.21 \pm 0.04$ & 8.4 & 13.10 & Strong & Low & Dark red \\
YT2 & $8.48 \pm 2.37$ & $1.82 \pm 0.22$ & $0.18 \pm 0.04$ & 8.0 & 13.91 & Light & Low & Bright red \\
YT3 & $7.94 \pm 2.34$ & $1.70 \pm 0.23$ & $0.18 \pm 0.04$ & 7.5 & 14.13 & Light & Low & Bright red \\
YT4 & $10.32 \pm 1.98$ & $2.30 \pm 0.28$ & $0.21 \pm 0.04$ & 6.7 & 12.61 & Strong & Low & Scarlet \\
YT1-1 & $9.51 \pm 2.17$ & $1.50 \pm 0.38$ & $0.18 \pm 0.06$ & 8.1 & 13.58 & Strong & Medium & Scarlet \\
YT1-2 & $8.88 \pm 0.98$ & $1.47 \pm 1.50$ & $0.19 \pm 0.05$ & 10.0 & 15.22 & Strong & High & Scarlet \\
YT2-1 & $8.90 \pm 2.09$ & $2.00 \pm 0.36$ & $0.19 \pm 0.05$ & 6.9 & 14.41 & Light & Low & Bright red \\
YT4-1 & $6.53 \pm 1.55$ & $1.68 \pm 0.26$ & $0.15 \pm 0.05$ & 8.5 & 13.33 & Light & Low & Bright red \\
YT4-2 & $10.97 \pm 2.04$ & $2.05 \pm 0.34$ & $0.20 \pm 0.06$ & 5.8 & 9.57 & Light & Low & Bright red \\
YT4-3 & $8.36 \pm 1.38$ & $1.38 \pm 0.25$ & $0.14 \pm 0.04$ & 9.1 & 13.25 & Strong & High & Bright red \\
KR1-1 & $7.97 \pm 2.64$ & $1.89 \pm 0.38$ & $0.17 \pm 0.03$ & 10.7 & 9.89 & Strong & Low & Dark red \\
KR1-2 & $7.47 \pm 2.35$ & $1.75 \pm 0.26$ & $0.15 \pm 0.05$ & 9.0 & 12.50 & Light & Low & Scarlet \\
KR1-3 & $10.86 \pm 1.92$ & $2.18 \pm 0.14$ & $0.21 \pm 0.04$ & 9.5 & 16.88 & Strong & Low & Dark red \\
KR1-4 & $9.80 \pm 1.69$ & $1.96 \pm 0.37$ & $0.15 \pm 0.04$ & 9.0 & 14.29 & Strong & Low & Scarlet \\
Chìa Vôi & $11.28 \pm 2.68$ & $2.06 \pm 0.23$ & $0.16 \pm 0.03$ & 4.1 & 9.83 & Strong & Low & Orange \\
\hline
\end{tabular}




\subsection{Yield and Yield Components}

By same weather condition and taking care techniques, productivity value shows preeminent variation. Yield depends on main factors, such as number of fruits per plant and fruit weight. The results of yield and yield components were recorded in Table 8 .

Number of commercial fruits ranged from 7.6 to 110.4 fruits. YT4-3 had the highest number of fruit (110.4 fruits), followed by YT1-1 (77.2 fruits) and YT1-2 (66.8 fruits). Some accessions had low number of fruits, such control check, YT1 and YT4-1. The remained accessions' number of fruit ranged from 34.8 to 49.6 . Followed observation, the reason caused low fruit number of few accessions was damaged by fruitworm.

Fruit weight depends on fruit size and fruit wall thickness. The biggest fruits were observed in KR1-4 (16.6 g) and KR1-3 (16.5 g). YT4, YT2-1, YT2 and control had almost equal fruit weight (ranging from $12.5 \mathrm{~g}$ to $13.1 \mathrm{~g}$ ).

Fruit weight and number of fruits decide the yield of pepper. All of pepper lines gave predicted and actual yields higher than the control check. YT4-3 gave the highest yield (28.31 tons/ha) and YT4-1 gave the lowest yield (3.71 tons/ha).

\subsection{Situation of Insects and Disease Affected on Pepper Germplasm}

Insects and diseases are reasons which caused yield and fruit quality decreases. Level of infected insects and diseases depends on resistant ability of variety or line. During experiment, many objects harmed peppers, such as cutworm, diamondback moth, fruitworm, bedbug, spider, etc., affected yield and fruit quality. Effects of worm and diseases on pepper germplasm were presented in Table 9.

\subsubsection{Cutworm (Ggrotis ipsilon Rott)}

Cutworm damaged pepper germplasm during experiment. Density of cutworm was observed the highest in YT3 line (4.78 individuals $/ \mathrm{m}^{2}$ ) and the lowest in YT4-1, YT4-2, KR1-1, KR1-2 and KR1-3 (none damage). Percentage of damaged plant was the highest in YT4 (60\%) and ranged from $20 \%$ to $40 \%$ in remaining accessions.

\subsubsection{Beet Armyworm (Spodoptera exigua)}

The highest density of this worm was recorded in YT4-2 line (7.83 individuals $\left./ \mathrm{m}^{2}\right)$ and its lowest was 0.43 individuals $/ \mathrm{m}^{2}$ in YT1-1. Percentage of harmed plant was the highest at $80 \%$ in YT1, YT2, YT1-2, YT4-1 and YT4-2. The remained accessions were damaged from $20 \%$ to $60 \%$.

Table 8 Yield and yield components of pepper germplasm.

\begin{tabular}{llllll}
\hline Accession & $\begin{array}{l}\text { Number of efficient } \\
\text { fruits per plant }\end{array}$ & $\begin{array}{l}\text { Number of commercial } \\
\text { fruits per plant }\end{array}$ & $\begin{array}{l}\text { Mean fruit weigh } \\
(\mathrm{g})\end{array}$ & $\begin{array}{l}\text { Predict yield } \\
\text { (ton/ha) }\end{array}$ & $\begin{array}{l}\text { Actual yield } \\
\text { ton/ha) }\end{array}$ \\
\hline YT1 & 9.2 & 8.6 & 15.5 & 5.33 & 5.49 \\
YT2 & 54.0 & 49.6 & 12.5 & 24.80 & 17.99 \\
YT3 & 39.0 & 34.8 & 10.0 & 13.92 & 13.26 \\
YT4 & 51.8 & 46.0 & 13.1 & 24.01 & 17.33 \\
YT1-1 & 91.2 & 77.2 & 9.0 & 27.79 & 19.70 \\
YT1-2 & 68.2 & 66.8 & 10.4 & 27.79 & 20.17 \\
YT2-1 & 55.2 & 47.0 & 12.9 & 24.25 & 23.01 \\
YT4-1 & 17.2 & 13.0 & 8.0 & 4.16 & 3.71 \\
YT4-2 & 49.8 & 40.0 & 10.1 & 16.16 & 15.25 \\
YT4-3 & 116.4 & 110.4 & 8.9 & 39.30 & 28.31 \\
KR1-1 & 41.2 & 40.6 & 9.6 & 15.59 & 14.24 \\
KR1-2 & 53.8 & 48.4 & 9.9 & 19.17 & 15.91 \\
KR1-3 & 41.0 & 36.0 & 16.5 & 23.76 & 20.17 \\
KR1-4 & 42.6 & 39.4 & 16.6 & 26.16 & 16.29 \\
Control & 9.4 & 7.6 & 13.1 & 3.98 & 1.42 \\
\hline
\end{tabular}


Table 9 Effect of worms and diseases on pepper germplasm.

\begin{tabular}{|c|c|c|c|c|c|c|c|}
\hline \multirow{3}{*}{ Accesion } & \multicolumn{4}{|c|}{ Worm } & \multicolumn{3}{|c|}{ Disease } \\
\hline & \multicolumn{2}{|c|}{ Cutworm } & \multicolumn{2}{|c|}{ Beet armyworm } & \multirow{2}{*}{$\begin{array}{l}\text { Fruitworm } \\
\text { Rate of harmed } \\
\text { fruit }(\%)\end{array}$} & \multirow{2}{*}{$\begin{array}{l}\text { Soft rot } \\
\text { Rate of harmed } \\
\text { fruit }(\%)\end{array}$} & \multirow{2}{*}{$\begin{array}{l}\text { Anthracnose } \\
\text { Rate of harmed } \\
\text { fruit }(\%)\end{array}$} \\
\hline & $\begin{array}{l}\text { Number of } \\
\text { individual } / \mathrm{m}^{2}\end{array}$ & $\begin{array}{l}\text { Percentage of } \\
\text { harmed plant }(\%)\end{array}$ & $\begin{array}{l}\text { Number of } \\
\text { individual } / \mathrm{m}^{2}\end{array}$ & $\begin{array}{l}\text { Rate of harmed } \\
\text { plant }(\%)\end{array}$ & & & \\
\hline YT1 & 0.43 & 20 & 3.48 & 80 & 13.04 & 0.00 & 6.52 \\
\hline YT2 & 1.74 & 20 & 6.09 & 80 & 11.85 & 0.37 & 0.37 \\
\hline YT3 & 4.78 & 40 & 2.61 & 60 & 10.26 & 3.08 & 1.54 \\
\hline YT4 & 2.61 & 60 & 2.17 & 60 & 7.72 & 0.39 & 0.00 \\
\hline YT1-1 & 0.87 & 20 & 0.43 & 20 & 2.41 & 0.66 & 0.44 \\
\hline YT1-2 & 0.43 & 20 & 2.61 & 80 & 1.17 & 0.88 & 0.29 \\
\hline YT2-1 & 0.43 & 20 & 0.87 & 40 & 11.96 & 13.04 & 1.81 \\
\hline YT4-1 & 0.00 & 0 & 3.04 & 80 & 10.47 & 1.16 & 3.49 \\
\hline YT4-2 & 0.00 & 0 & 7.83 & 80 & 2.41 & 1.20 & 1.61 \\
\hline YT4-3 & 1.30 & 40 & 3.91 & 60 & 2.75 & 1.03 & 0.86 \\
\hline KR1-1 & 0.00 & 0 & 2.61 & 40 & 2.91 & 1.46 & 0.00 \\
\hline KR1-2 & 0.00 & 0 & 1.74 & 40 & 2.60 & 0.37 & 0.00 \\
\hline KR1-3 & 0.00 & 0 & 2.17 & 60 & 3.41 & 0.00 & 0.98 \\
\hline KR1-4 & 1.74 & 20 & 1.30 & 40 & 3.29 & 1.41 & 1.41 \\
\hline Control & 0.87 & 20 & 0.87 & 40 & 8.51 & 6.38 & 10.64 \\
\hline
\end{tabular}

\subsubsection{Fruitworm (Helicoverpa armigera Hiibner)}

YT1 line was highly damaged at $13.04 \%$ by fruitworm, next ones were YT2, YT2-1, YT4-1 at $11.85 \%, 11.96 \%, 10.47 \%$, respectively. The remained accessions were damaged by low percentage from $1.17 \%$ to $8.51 \%$.

\subsubsection{Soft Rot (Erwinia carotovora)}

The damage by soft rot was found the highest in YT2-1 (13.04\%), followed by control check (6.38\%) and YT3 (3.08\%). YT1 and KR1-3 were not damaged by this disease.

\subsubsection{Anthracnose (Colletotrichum capsici)}

Control accession had the highest rate of infection of anthracnose at $10.64 \%$, next ones were at YT1 (6.52\%) and YT4-1 (3.49\%) lines. YT4, KR1-1 and KR1-2 were not infected by this disease. The remained accessions had damaged rate ranging from $0.29 \%$ to $1.81 \%$.

\section{Conclusions}

As a result, the induced pepper germplasms were harvested earlier and had higher yield and better quality compared with the control. The induced pepper accessions are diversed in morphological and agronomical features, as plant height, number of leaves or branches, colour of leaf, flower and fruit. YT2-1 had the highest percentage of effective flowers (80.38\%), YT1-2 gave the highest percentage of fruiting $(68.2 \%)$, whereas YT4-3 reached the highest yield (28.31 tons/ha). These pepper lines should be used for breeding of high yield varieties. YT1-1 was resistant to insects and diseases and should be used in breeding program for insect and disease resistance. YT1-2 showed good adaptability and fruit quality compared with other accessions under Thua Thien Hue weather conditions. The induced pepper lines which gave good characteristics should be designed in next experiments in different seasons and ecological areas to assess their potentiality to complete crop structure.

\section{References}

[1] Food and Agriculture Organization of the United Nations (FAO). 2013. "FAOSTAT." Accessed November, 2015. www.fao.org.

[2] Joshi, S., Thakur, P. C., Verma, T. S., and Werma, H. C. 1993. "Selection of Spice Paprika Breeding Lines." Capsicum and Eggplant Newsletter 12: 50-2.

[3] Dexiang, C. 1994. Hot Pepper Varietal Trial. The 12th Regional Training Report in Vegetable Production and 
Research, ARC-AVRDC.

[4] Cannon, P. F., Bridge, P. D., and Monte, E. 2000. "Linking the Past, Present and Future of Colletotrichum Systematics." In Colletotrichum: Host Specificity, Pathology and Host-Pathogen Interaction, edited by Prusky, D., Freeman, S., and Dickman, M. B. St. Paul, Minnesota: APS Press, 1-20.

[5] Agradi, E., Regondi, S., and Rotti, G. 2005. Aspects of Pharmaceutical Botany: Learn about Medicinal Plants. Vol. 4. Italy: MediService, 154-6. (in Italian)

[6] Mai, P. A., Tran, V. L., and Tran K. T. 1995. Vegetables. Ha Noi: Agriculture Publish House, 183-9. (in Vietnamese)

[7] Anh, M. T. P. 1999. Vegetable Cultivation. Ha Noi: Farmer Publish House, 5-11. (in Vietnamese)
[8] Ministry of Agriculture and Rural Development (MARD). 2011. Circular No. 48/2011/TT-BNNPTNT of the Ministry of Agriculture and Rural Development on National Technical Regulation on Crop Trial. (in Vietnamese)

[9] Bosland, P. W. 1992. "Chiles: A Diverse Crop." Hort. Technol. 2 (1): 6-10.

[10] Bosland, P. W. 1994. "Chillies History, Cultivation and Uses.” In Species, Herbs and Edible Fungi. New York, USA: Elsevier Publication, 347-66.

[11] Akinci, S., and Akinci, I. E. 2004. "Evaluation of Red Pepper for Spice (Capsicum annuum L.) Germplasm Resource of Kahramanmaras Region (Turkey).” Journal of Biological Sciences 7 (5): 703-10. 